\title{
Flow cytometric analysis of DNA synthetic phase fraction of the normal appearing colonic mucosa in patients with colorectal neoplasms
}

\author{
S Nakamura, J Goto, Y Kitayama, J P Sheffield, I C Talbot
}

Division of Pathology, Clinical Central Laboratory, School of Medicine Iwate Medical University, Japan

S Nakamura

Research Equipment Centre

J Goto

and First Department of Pathology

Y Kitayama

Hamamatsu

University School of

Medicine,

Hamamatsu, Japan

Department of Pathology and ICRF Colorectal Cancer Unit, St Mark's

Hospital, London

J P Sheffield

I C Talbot

Correspondence to: Dr Shin-ichi Nakamura, Division of Pathology, Clinical Central Laboratory, School of Medicine Iwate Medical University, 19-1 Uchimaru, Morioka 020, Japan.

Accepted for publication 31 December 1994

\begin{abstract}
DNA synthetic (S) phase fractions of normal appearing colonic mucosa in Japanese and British patients with colorectal neoplasms were compared with those in patients without colonic neoplasms. Normal crypts were isolated from fresh surgical specimens of the large intestine by the use of EDTA. After fixation with $70 \%$ ethanol, isolated crypts were digested with pepsin into single nuclei suspensions. These were stained with propidium iodide and examined by flow cytometry. S phase fraction was calculated from the flow cytometry DNA histogram using Baisch's method. $S$ phase fractions of normal appearing crypts in Japanese and British patients with colorectal tumours were not significantly different and analysed together. $S$ phase fraction of normal appearing colonic crypts in 14 patients with familial adenomatous polyposis (FAP) was $10 \cdot 23(2 \cdot 59) \%$ (mean (SD)) ranging from 5.8 to $18 \cdot 8$. S phase fraction of background normal mucosa in patients with large adenomas (over $2 \mathrm{~cm}$ ) and adenocarcinomas were $9.74(3.76) \%$ (range, 2.7-16.1) and 8.93 (3.54)\% (range, 2.9-18.9) respectively. In normal mucosa of patients without any colorectal neoplasms, $S$ phase fraction was $8.99(3.94) \%$ (range, 3.9-17.7). There was no statistically significant difference in $\mathbf{S}$ phase fractions of normal mucosa in the four groups. Our results show that an increase in proliferative activity of background colonic crypts is not necessary for tumour development.

(Gut 1995; 37: 398-401)
\end{abstract}

Keywords: adenoma, carcinoma, DNA ploidy, familial adenomatous polyposis, flow cytometry, $\mathrm{S}$ phase fraction.

Lipkin proposed that, in the morphogenesis of colorectal neoplasia, an expansion of the crypt proliferative zone with increased cellular proliferation preceded tumour development. ${ }^{1}$ Many investigators have supported his proposal by examining the labelled cell position in colorectal mucosa using in vitro autoradiography ${ }^{3}$ or in vitro bromodeoxyuridine labelling. ${ }^{4}$ In familial adenomatous polyposis, sporadic cancer, and even adenoma patients, workers have shown an expanding proliferative zone with increasing proliferative activity in normal appearing colorectal mucosa. ${ }^{5-7}$
Using a complete serial sectioning technique, we found that adenomas in familial adenomatous polyposis patients begin to develop in the proliferative zone of the lower crypts in the form of atypical epithelial clusters - that is 'bud of adenoma' ${ }^{8} \mathrm{We}$ also examined whether upward expansion of proliferative zone actually occurred in the normal appearing colonic mucosa using ex vivo autoradiography. ${ }^{9}$ Our results conflicted with Lipkin's theory, and showed that in familial adenomatous polyposis patients the proliferative compartment was identical to sporadic colorectal cancer patients: the proliferative compartment was located in the lower two thirds of the crypts with a similar labelling index in the two groups. ${ }^{10}$ Using cytophotometry, we compared the nuclear DNA content of epithelial cells in the lower two thirds and the upper one third of isolated colonic crypts in familial adenomatous polyposis and sporadic colorectal cancer groups. This showed that the upper one third of crypts had only a diploid DNA content and the lower two thirds also had a diploid population as well as a proliferative compartment in both groups. ${ }^{11}$

Both autoradiographic and cytophotometric techniques are tedious and score only a small number of cells. DNA flow cytometry, however, can analyse a large number of cells rapidly. It has been used to study DNA ploidy and cellular proliferative activities in various neoplasms. ${ }^{12} 13$ Conventional flow cytometry techniques have inevitably analysed both epithelial and normal stromal cells and pure epithelial DNA ploidy and proliferative activities have rarely been ascertainable. ${ }^{1415}$ To improve this inadequacy we have applied the crypt isolation technique to flow cytometry. Crypt isolation has allowed us to analyse the accurate DNA ploidy of various colorectal neoplasms. ${ }^{16}$

In this paper, we report the $S$ phase fraction of background non-neoplastic mucosa in groups of various colorectal neoplastic conditions in comparison with a control group without large bowel neoplasia using flow cytometry following crypt isolation.

\section{Methods}

\section{Clinical material}

Between 1989 and 1992, tissue for the study was taken from 93 patients with colorectal neoplasms undergoing resection of the large intestine in Hamamatsu University Hospital (Hamamatsu, Japan) and in related city hospitals. A further 29 patients undergoing 
TABLE I Clinical data of patients in two hospitals

\begin{tabular}{lcccl}
\hline $\begin{array}{l}\text { Colorectal } \\
\text { tumour }\end{array}$ & $\begin{array}{c}\text { Patients } \\
(n)\end{array}$ & $\begin{array}{c}\text { Males/ } \\
\text { females }\end{array}$ & $\begin{array}{l}\text { Mean age } \\
\text { (range) }\end{array}$ & $\begin{array}{l}\text { Samples } \\
(n)\end{array}$ \\
\hline Hamamatu & University & Hospital, Hamamatsu, fapan & \\
FAP & 7 & $4 / 3$ & $41 \cdot 6(22-56)$ & 10 \\
Adenoma & 15 & $6 / 9$ & $66 \cdot 5(41-81)$ & 15 \\
SCRC & 71 & $36 / 35$ & $63 \cdot 4(34-88)$ & 71 \\
St Mark's & Hospital, London, United & Kingdom & \\
FAP & 7 & $5 / 2$ & $22 \cdot 9(17-31)$ & 19 \\
SCRC & 15 & $7 / 8$ & $64 \cdot 1(43-83)$ & 15 \\
Control & 7 & $3 / 4$ & $38 \cdot 4(25-61)$ & 13 \\
\hline
\end{tabular}

^FAP, familial adenomatous polyposis; SCRC, sporadic colorectal cancer.

large bowel resection at St Mark's Hospital (London, UK) between July 1992 and March 1993, were also analysed.

Fourteen patients had colectomies for familial adenomatous polyposis, 15 patients had tubular or villous adenomas with mild to moderate atypia and more than $2 \mathrm{~cm}$ in size, 86 patients had adenocarcinomas, and seven patients had colectomies for dysfunctional colorectal diseases such as constipation, intussusception, megacolon and perineal pain (Table I).

Fresh specimens were obtained immediately after surgical excision. Normal mucosa at least $5 \mathrm{~cm}$ from the neoplasms was separated from the submucosa with scissors. Flat mucosa between multiple adenomas in familial adenomatous polyposis cases was also sampled. In the cases with non-neoplastic disease, normal mucosa without any inflammation was selected. In total colectomy cases, samples were routinely obtained from the ascending, transverse, and descending colons to be analysed separately. Rectal mucosal samples were not used in this study.

\section{Crypt isolation}

The method of Arai and Kino was used for crypt isolation. ${ }^{17}$ Briefly, fresh mucosa was cut to a $5 \mathrm{~mm}$ square with a razor. This was then incubated at $37^{\circ} \mathrm{C}$ for 30 minutes in calcium and magnesium free Hanks's balanced salt solution containing $30 \mathrm{mM}$ EDTA. After this the tissue was stirred in calcium and magnesium free Hanks's balanced salt solution. Normal crypts were separated from the lamina propria mucosa with 30 to 40 minutes. The isolated crypts were promptly fixed in $70 \%$ ethanol and stored at $4^{\circ} \mathrm{C}$.

\section{Identification of crypts}

Fixed crypts were observed under a dissecting microscope (SZ60, Olympus, Tokyo) with normal and neoplastic crypts showing characteristic three dimensional features. Haematoxylin and eosin stained sections of paraffin wax embedded crypts confirmed their histological origins. Adenomatous crypts were usually intermingled with normal crypts in familial adenomatous polyposis patients and required careful separation. ${ }^{11}$

Flow cytometry

Normal crypts of each patient were incubated with $0.0125 \%$ pepsin $(\mathrm{pH} 2.0$, Sigma, St
Louis, MO) for five minutes at $37^{\circ} \mathrm{C}$, washed twice with $0.2 \mathrm{M}$ TRIS chloride buffered saline, and syringed through a 27 gauge needle. Normal nuclei was stained with propidium iodide $(50 \mu \mathrm{g} / \mathrm{ml}$, Sigma) containing ribonuclease $(0.25 \mathrm{mg} / \mathrm{ml}$, Sigma) in $0.2 \mathrm{M}$ TRIS chloride buffered saline for 30 minutes in darkness at room temperature. After filtering through $37 \mu \mathrm{m}$ nylon mesh (Tokyo Screen, Tokyo), samples were analysed on an EPICS PROFILE (Coulter, Hialeah, FL). An argon ion laser was used at $15 \mathrm{~mW}$ at a wavelength of $488 \mathrm{~nm}$ for excitation. Emission was measured using a $610 \mathrm{~nm}$ long pass filter. Ten thousand nuclei were counted in each sample. No extrinsic external control was used in this study.

\section{Histogram interpretation}

DNA histograms were analysed using the software package Cytologic (Coulter Corporation). All samples of normal mucosa have only one G0/G1 peak, which was regarded as diploid stemline. Overlapped nuclei of G0 or G1 phase - that is, doublet have a lower peak pulse than that of single nuclei of G2 phase on measurement of DNA content by flow cytometer. These doublets can be excluded from single nucleus population on the scattergram. S phase fraction was calculated by using a rectangular computer software model of Baisch et al. ${ }^{18}$ The coefficient of variation (CV) of each group was calculated as full width CV. All samples in this study were measured more than twice and the samples with a lower $\mathrm{CV}$ were used for $\mathrm{S}$ phase fraction analysis.

\section{Histopathology}

All resected surgical materials were routinely examined on paraffin wax embedded, haematoxylin and eosin stained sections. Diagnoses of epithelial tumours including familial adenomatous polyposis, adenoma, and carcinoma and of cases without colorectal neoplasms were made. The tissue fragments remaining after crypt isolation were fixed with $70 \%$ ethanol and examined histologically. These fragments show some remaining crypts that enabled estimation of the character of isolated crypts.

\section{Statistical analysis}

A non-parametric Mann-Whitney U test was used for statistical analysis using StatView-II software (Abacus Concepts, Berkeley, CA). Values of mean (SD) of $C V$ and $S$ phase fraction of each group were calculated. A value of significance of $p<0.05$ was assumed.

\section{Results}

Crypts of normal mucosa were easily separated from lamina propria mucosa by agitation of fragments obtained from incubation with EDTA. Under the dissecting microscope normal crypts had regular test tube like appearance and were up to $1 \mathrm{~mm}$ in length. This was confirmed histologically. Small or large crypts 
TABLE II Values of $S$ phase fraction and coefficient of variation (CV) of background colonic mucosa in 122 patients

\begin{tabular}{|c|c|c|c|}
\hline Tumour & $\begin{array}{l}\text { Samples } \\
(n)\end{array}$ & $\begin{array}{l}\text { S phase fraction } \\
\text { (mean (SD)) (range) }\end{array}$ & $C V$ (mean (SD)) (range) \\
\hline $\begin{array}{l}\text { FAP } \\
\text { SCRC } \\
\text { Adenoma } \\
\text { Control }\end{array}$ & $\begin{array}{l}29 \\
86 \\
15 \\
13\end{array}$ & $\begin{array}{r}10 \cdot 23(2.59)(5 \cdot 8-18 \cdot 8) \\
8.93(3.54)(2 \cdot 9-18 \cdot 9) \\
9.74(3.76)(2 \cdot 7-16 \cdot 1) \\
8.99(3.94)(3.9-17 \cdot 7)\end{array}$ & $\begin{array}{l}2.65(0.65)(1.40-3.86) \\
2 \cdot 82(0.54)(1.59-4.57) \\
2.99(0.52)(2.27-3.72) \\
2.38(0.63)(1.60-3.40)\end{array}$ \\
\hline
\end{tabular}

Abbreviations as in Table I.

and those having branches were avoided. Crypts of microscopic and single gland adenomas $^{8}$ found in familial adenomatous polyposis cases were usually irregular and larger than normal crypts. Their nature was confirmed on paraffin wax embedded, haematoxylin and eosin stained histological sections. ${ }^{11}$

A G0/G1 peak on DNA histogram of normal crypts measured by flow cytometry was defined as diploid and no multiple peaks were seen throughout the study. In the familial adenomatous polyposis group, values of $S$ phase fraction of Japanese and British cases were as follows: $10 \cdot 11(1 \cdot 77) \%$ (range, $7 \cdot 9-12 \cdot 4$ ) and 10.30 $(2.97) \%$ (range, 5.8-18.8). There was no statistically significant difference in the values of $S$ phase fraction between the two countries.

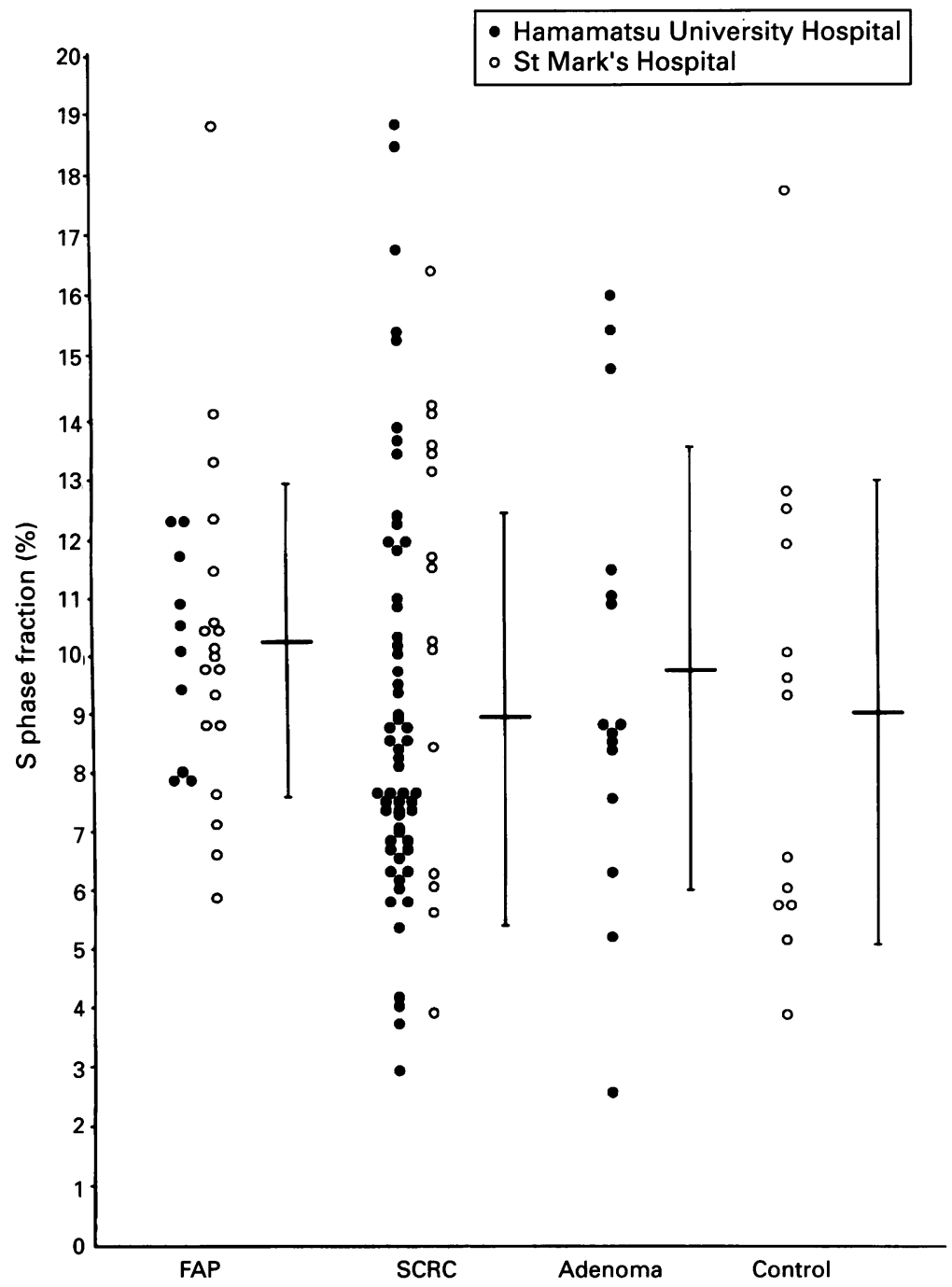

All values of $S$ phase fraction are plotted on a chart. Closed circles show the cases of Hamamatu University Hospital and open circles, St Mark's Hospital. Four vertical lines with median short lines show the means and standard deviations of each four groups. $F A P=$ familial adenomatous polyposis; $S C R C=$ sporadic colorectal cancer.
In the sporadic cancer groups, values of $S$ phase fraction were also compared between Japanese and British cases as follows: 8.59 (3.42) \% (range, $2.9-18.9)$ and $10.58(3.74) \%$ (range, 3.9-16.4). There was no significant statistical difference in the values of $S$ phase fraction between the two countries. Consequently, Japanese and British cases were analysed together in the familial adenomatous polyposis and cancer groups. There were no British cases of large adenoma and Japanese cases were used for the comparison. There were no Japanese control cases and British cases were used as control.

The mean values of $S$ phase fraction of the four groups were calculated as follows: familial adenomatous polyposis, $10 \cdot 23(2 \cdot 59)$; sporadic colorectal cancer, 9.83 (3.54); adenoma, 9.74 (3.76); and control, 8.99 (3.94) (Table II). The Figure shows the values of $S$ phase fraction of all cases in the four groups. No significant difference of $S$ phase fraction was found statistically between all four groups.

The mean CV of each of the four groups was as follows: familial adenomatous polyposis, 2.65 (0.65); cancer, $2.82(0.54)$; adenoma, $2.99(0.52)$; and control, $2.38(0.63)$ (Table II).

\section{Discussion}

Most investigators supporting Lipkin's proposal, have used an in vitro autoradiography or bromodeoxyuridine labelling method to examine the distribution of proliferative zones of colorectal mucosa obtained by biopsy. ${ }^{2-7} \mathrm{We}$ have pointed out several disadvantages in the application of in vitro autoradiography to biopsy material, and consequently developed ex vivo autoradiography, which has enabled us to use surgically resected colon for autoradiography. ${ }^{9}$ Well oriented crypts cut longitudinally were analysed using this method and no expansion was found in either familial adenomatous polyposis or sporadic colorectal cancer. The labelling index was also the same in both groups. ${ }^{10}$ Distribution of the DNA content of epithelial cells in isolated normal crypts was also analysed using cytophotometry and no expansion of proliferative zone was found in either familial adenomatous polyposis or the sporadic colorectal cancer groups. ${ }^{11}$

In both of our previous experiments we had no 'control' colons without neoplasms. Total or partial colectomies are performed in patients who suffer from constipation, volvulus of the sigmoid colon, megacolon and some other dysfunctional disorders of colorectum at St Mark's Hospital. These resected colons, which had no incidental epithelial neoplasia, were used as a control group in this experiment.

Nsien et al reported the flow cytometric analysis of normal appearing colorectal mucosa in normal, adenoma, and carcinoma patients. They failed to show abnormalities of DNA content in groups with adenoma or carcinoma. ${ }^{15}$ They mentioned some possibilities why they failed to disclose abnormal proliferative activity in tumour groups; one being that 
abundant normal stromal cells would mask abnormal epithelial populations on the flow cytometry DNA histogram.

We have pointed out several problems of conventional flow cytometry and to improve the method we applied the crypt isolation technique to flow cytometry. ${ }^{16}$ Using this method we can calculate $S$ phase fraction of epithelial cells accurately without contamination by interstitial cells. The values $(8 \cdot 9-10 \cdot 2 \%)$ of $S$ phase fraction of our study were comparable with the labelling indices $(9 \cdot 9-11 \cdot 6 \%)$ by in vitro autoradiography ${ }^{5}$ and the overall mean labelling index $(10.3 \%)$ by in vivo bromodeoxyuridine labelling. ${ }^{19}$

The death rates of colorectal malignant neoplasms per 100000 population in Japan versus England and Wales were: men, $22.1 v 34.5$ and women, $18.3 v 33.4 .{ }^{20}$ Regional differences of the incidence of colorectal malignancy between the two countries might be caused by dietary factors because high protein and fat, and low fibre in the diet may be regarded as possible risk factors of colorectal carcinomas. ${ }^{21}$

Cell kinetic studies of colorectal mucosa exposed to chemical carcinogens has been conducted in experimental animals with both expansion and hyperproliferation of the proliferative compartment demonstrated in normal appearing crypts. This has been considered as a preceding event in carcinogenesis and therefore as a risk factor for cancer. ${ }^{22} 23$ According to these results, proliferative activity of the crypts in British cases might be higher than in Japanese cases. Our results, however, showed no significant differences in familial adenomatous polyposis and sporadic colorectal cancer groups from both countries.

We examined the proliferative compartment and activities of colonic crypts of mice treated with dimethylhydrazine and found that the proliferative compartment was slightly expanded in the experimental group compared with the control group but proliferative activity was the same in both groups. Direct toxic effect of chemical carcinogen might cause temporary damage of crypt epithelia and following the regenerative process result in the slight expansion of the proliferative compartment. ${ }^{24}$

We have previously pointed out the limitation of cell kinetic studies using biopsy material by in vitro autoradiography..$^{10} \mathrm{We}$ also stress that 'normal' crypts have to be used for interpretation of cell kinetic analysis. We avoided rectal mucosa in this study because rectal crypts are often hyperplastic, branching, and tortuous even in healthy patients. Minor mucosal injury or focal mucosal prolapse may occur at defecation and the subsequent reparative process may cause 'abnormal' crypts. It is essential to evaluate the 'normal' crypts for the analysis of cell kinetics of the crypt epithelium.

The conclusion of this study confirmed our previous results and showed no hyperproliferation of histologically normal crypts in the colorectum in patients with neoplasia. 8101124

We are grateful to Mr Moriyasu Oikawa for statistic analysis.

1 Lipkin M. Phase 1 and phase 2 proliferative lesions of colonic epithelial cells in diseases leading to colonic cancer. Cancer 1974; 34: 878-88.

2 Deschner EE, Lipkin M. Proliferative patterns in colonic mucosa in familial polyposis. Cancer $1975 ; 35: 413-8$.

3 Iwama T, Utsunomiya J, Sasaki J. Epithelial cell kinetics in the crypts of familial polyposis of the colon. fpn f Surg 1977; $7: 230-4$

4 Risio M, Lipkin M, Candelaresi GL, Bertone A, Coverlizza S, Rossini FP. Correlations between rectal mucosa cell proliferation and the clinical and pathological features of proliferation and the clinical and pathological features of
nonfamilial neoplasia of the large intestine. Cancer Res nonfamilial neoplasia

5 Paganelli GM, Biasco G, Santucci R, Brandi G, Lalli AA, Miglioli M, et al. Rectal cell proliferation and colorectal cancer risk level in patients with nonfamilial adenomatous polyps of the large bowel. Cancer 1991; 68: 2451-4.

6 Witzig TE, Loprinzi CL, Gonchoroff NJ, Reiman HM, Cha SS, Wieand HS, et al. DNA ploidy and cell kinetic measurements as predictors of recurrence and survival in stages B2 and C colorectal adenocarcinoma. Cancer 1991; 68: $879-88$.

7 Roncucci L, Scalmati A, Ponz de Leon M. Pattern of cell kinetics in colorectal mucosa of patients with different kinetics in colorectal mucosa of patients with different
types of adenomatous polyps of the large bowel. Cancer 1991; 68: 873-8.

8 Nakamura S, Kino I. Morphogenesis of minute adenomas in familial polyposis coli. $\mathscr{f}$ Natl Cancer Inst 1984; 73: 41-9.

9 Nakamura S, Kino I, Baba S. Ex vivo autoradiography of the human gastrointestinal tract: a new approach to cell kinetic studies of surgically removed tumour-bearing organs. Fpn f Cancer Res 1983; 74: 116-21.

10 Nakamura S, Kino I, Baba S. Cell kinetics analysis of background colonic mucosa of patients with intestinal neoplasms by ex vivo autoradiography. Gut 1988; 29: 997-1002.

11 Nakamura S, Kino I, Baba S. Nuclear DNA content of isolated crypts of background colonic mucosa from patients with familial adenomatous polyposis and sporadic colowith familial adenomatous polyposis
rectal cancer. Gut 1993; 34: 1240-4.

12 Seckinger D, Sugarbaker E, Frankfurt O. DNA content in human cancer. Application in pathology and clinical medicine. Arch Pathol Lab Med 1989; 113: 619-26.

13 Sasaki K, Murakami T. Clinical application of flow cytometry for DNA analysis of solid tumors. Acta Pathol $\mathfrak{f p}_{p}$ 1992; 42: 1-14.

14 Kouri M, Pyrhonen S, Mecklen J-P, Jarvinen H, Laasonen A, Franssila K, et al. The prognostic value of DNA-ploidy in colorectal carcinoma: a prospective study. $\mathrm{Br} \mathcal{F}$ Cancer 1990; 62: 976-81.

15 Nsien E, Steinberg WM, Wilkinson DS, Rhame JG, Henry JP. Single-parameter DNA flow cytometric analysis of normal-appearing colonic mucosa does not predict the presence of colonic neoplasia. Am $\mathcal{F}$ Gastroenterol 1991; 86: $1477-81$.

16 Nakamura S, Goto J, Kitayama M, Kino I. Application of crypt isolation technique to flow cytometric analysis of DNA content in colorectal neoplasms. Gastroenterology 1994; 106: 100-7.

17 Arai T, Kino I. Morphometrical and cell kinetic studies of normal human colorectal mucosa. Comparison between the proximal and distal large intestine. Acta Pathol fpn 1989; 39: 725-30.

18 Baisch H, Goehde W, Linden WA. Analysis of PCP-data to determine the fraction of cells in the various phases of cell cycle. Radiat Environ Biophys 1975; 12: 31-9.

19 Potten CS, Kellett M, Rew DA. Proliferation in human gastrointestinal epithelium using bromodeoxyuridine in vivo: data for different sites, proximity to a tumour, and polyposis coli. Gut 1992; 33: 524-9.

20 World Health Organization. World health statistics annual. Geneva: 1991.

21 Wargovich MJ, Baer AR, Hu PJ, Sumiyoshi H. Dietary factors and colorectal cancer. Gastroenterology Clin North Am 1988; 17: 727-45.

22 Galloway DJ, Jarrett F, Boyle P, Indran M, Carr K, Owen $\mathrm{RW}$, et al. Morphological and cell kinetic effects of dietary manipulation during colorectal carcinogenesis. Gut 1987; 28: 754-63.

23 Yamada K, Yoshitake K, Sato M, Ahnen DJ. Proliferating cell nuclear antigen expression in normal, preneoplastic, and neoplastic colonic epithelium of the rat. and neoplastic colonic epith

24 Nakamura S, Kino I. Morphogenesis of experimental colonic neoplasms induced by dimethylhydrazine. Pfeiffer CJ, ed. Animal models for intestinal disease. Boca Raton, Florida: CRC Press, 1985: 99-122. 